\title{
Aortic diameter predicts acute type A aortic dissection in patients with Marfan syndrome but not in patients without Marfan syndrome
}

\author{
Eun Kyoung Kim, MD, ${ }^{\mathrm{a}}$ Seung Hyuk Choi, MD, PhD, ${ }^{\mathrm{a}}$ Kiick Sung, MD, PhD, ${ }^{\mathrm{b}}$ Wook Sung Kim, MD, PhD, ${ }^{\mathrm{b}}$ \\ Yeon Hyeon Choe, MD, PhD, ${ }^{\mathrm{c}}$ Jae K. Oh, MD, PhD, ${ }^{\text {a,d }}$ and Duk-Kyung Kim, MD, PhD ${ }^{\mathrm{a}}$
}

\begin{abstract}
Objectives: Among the parameters for surveillance of patients at risk of acute type A aortic dissection, the aortic size has been considered a cardinal factor. Preventive surgery of the aorta in asymptomatic patients on the basis of size alone is still controversial in patient populations lacking other risk factors for aortic dissection. The aim of the present study was to assess the value of the aortic diameter as a current criterion for elective aortic surgery to prevent the development of aortic dissection in patients without and with Marfan syndrome (MFS).

Methods: We reviewed the data from patients diagnosed with acute type A aortic dissection from December 1994 to March 2009 at our institute. A total of 237 patients who presented with acute type A aortic dissection were enrolled, of whom 31 were diagnosed with MFS.

Results: The maximal ascending aorta size was $46.7 \mathrm{~mm}$ (range, 42.9-51.6) in non-MFS patients and $58.5 \mathrm{~mm}$ (range, 43.8-64.9) in MFS patients $(P<.001)$. Two thirds $(74 \%)$ of the MFS patients had a maximal aortic root size of $\geq 45 \mathrm{~mm}$. However, $87 \%$ of the 206 non-MFS patients had an aortic diameter $<55 \mathrm{~mm}$. Non-MFS patients presenting with an aortic size $<55 \mathrm{~mm}$ developed aortic dissection at a younger age and had a higher body mass index than those with an aortic size $\geq 55 \mathrm{~mm}$.
\end{abstract}

Conclusions: Type A aortic dissection occurs in smaller aortas in non-MFS patients compared with those with MFS. (J Thorac Cardiovasc Surg 2014;147:1505-10)

Aortic dissection is a life-threatening condition in which early diagnosis, treatment, and close follow-up are critical for survival. About $60 \%$ to $70 \%$ of patients with acute dissection are affected at the ascending aorta, classified as Stanford type A. ${ }^{1}$ The mortality and morbidity of ascending aortic dissection are more critical than that of any other types of acute aortic syndrome. The known risk factors for ascending aortic dissection include hypertension, a bicuspid aortic valve, aortic aneurysm, and intrinsic aortic tissue abnormalities, which can include Marfan syndrome (MFS), Loeys-Dietz syndrome, and Ehlers-Danlos syndrome., ${ }^{2,3}$

Of the parameters considered during watchful follow-up for the genesis of acute type A aortic dissection, the aortic size has been considered a cardinal factor for the development of acute dissection. ${ }^{4}$ The size of the aorta is a critical

\footnotetext{
From the Division of Cardiology, ${ }^{\mathrm{a}}$ Department of Medicine, Cardiovascular Imaging Center, Samsung Medical Center, Department of Thoracic and Cardiovascular Surgery, ${ }^{\mathrm{b}}$ and Department of Radiology and Center for Imaging Science, ${ }^{\mathrm{c}}$ Sungkyunkwan University School of Medicine, Seoul, Republic of Korea; and Division of Cardiovascular Diseases, ${ }^{\mathrm{d}}$ Mayo Clinic College of Medicine, Rochester, Minn.

This work was supported by the Samsung Biomedical Research Institute (grant C-A9204-3).

Disclosures: Authors have nothing to disclose with regard to commercial support.

Received for publication Jan 29, 2013; revisions received April 1, 2013; accepted for publication May 23, 2013; available ahead of print July 22, 2013.

Address for reprints: Duk-Kyung Kim, MD, PhD, Division of Cardiology, Department of Medicine, Cardiac and Vascular Center, Samsung Medical Center, Sung-

kyunkwan University School of Medicine, No. 81 Irwon-ro, Gangnam-gu, Seoul 135-710, Korea (E-mail: dkkim@skku.edu).

$0022-5223 / \$ 36.00$

Copyright (C) 2014 by The American Association for Thoracic Surgery

http://dx.doi.org/10.1016/j.jtcvs.2013.05.025
}

issue with regard to prophylactic surgery and the optimal timing of aortic replacement, especially in patients with connective tissue abnormalities such as MFS. ${ }^{5}$ The current guideline to prevent aortic dissection in non-MFS and MFS patients suggests that elective aortic surgery is required when the maximal ascending aorta size has reached $55 \mathrm{~mm}$ for non-MFS patients and $45 \mathrm{~mm}$ for MFS patients. ${ }^{6,7}$

However, previous studies have found that the incidence of aortic dissection did not decrease, regardless of elective aortic replacement therapy. ${ }^{8,9}$ Furthermore, preventive surgery of the aorta in asymptomatic patients on the basis of aortic size alone remains controversial in patient populations without known risk factors for aortic dissection. ${ }^{6,10,11}$ Some studies have shown that an increased aortic size as a follow-up parameter was not sufficient to predict aortic dissection or rupture. ${ }^{12,13}$

The aim of the present study was to assess the feasibility of the aortic diameter as a current criterion for elective aortic surgery to prevent the development of aortic dissection in non-MFS and MFS patients. We investigated the possible correlation between the aortic diameter and the occurrence of acute Stanford type A aortic dissection.

\section{METHODS}

Data on all aortic dissections diagnosed from December 1994 to March 2009 were retrieved from the aortic dissection registry at our institute, 1 of the largest medical centers in Korea. A retrospective analysis of all patients with acute type A aortic dissection was conducted. According to the 


\section{Abbreviation and Acronym \\ MFS = Marfan syndrome}

Stanford classification, type A aortic dissection was defined as any dissection involving the ascending aorta.

Acute dissection was defined as the presentation of any dissection within 14 days of symptom onset. Patients presenting with any dissection after 14 days of symptom onset were excluded to ensure an accurate analysis of the correlation between the aortic size and the occurrence of dissection. We excluded patients who had developed aortic dissection from other causes, such as Loeys-Dietz syndrome, Ehlers-Danlos syndrome, familial thoracic aortic aneurysm and dissection, and trauma. The diagnosis of MFS was determined strictly by the presence of manifestations defined by the Ghent nosology. The variables of interest included demographic data, medical history, and imaging results. Hypertension was defined as systolic blood pressure $>140 \mathrm{~mm} \mathrm{Hg}$ or a self-reported history of hypertension with or without ongoing pharmacologic treatment. Diabetes mellitus was defined as a history of type 1 or type 2 diabetes mellitus, treated pharmacologically or controlled by diet.

To identify the factors influencing the development of aortic dissection, we checked for the presence or absence of atherosclerosis, penetrating aortic ulcer, and simple renal cyst. ${ }^{14-16}$ Measuring the thickness of the intimal and medial layers of the aortic wall, mild and severe atherosclerosis was defined according to whether the layer was $>4$ or $<4 \mathrm{~mm} .{ }^{14}$ A penetrating aortic ulcer was defined as an atherosclerotic lesion with ulceration that had penetrated the internal elastic lamina and allowed hematoma formation within the medial layer of the aortic wall. ${ }^{17} \mathrm{~A}$ simple renal cyst was defined on the basis of a computed tomography scan as a thin-walled, lowattenuation, oval to round lesion with a diameter of $\geq 5 \mathrm{~mm}$, without evidence of enhancement or septation.

To evaluate aortic dilatation in each patient, we measured the maximal dimension at each level of the aorta using computed tomographic angiography. ${ }^{18-20}$ The ascending aorta, which extends from the root to the origin of the right brachiocephalic artery, was measured at the root and tubular ascending segment. ${ }^{21}$ To describe the relative aortic size, we measured the diameter of the aorta in a varying plane level. We measured the aortic root size at the aortic valve annulus, sinus of Valsalva, and the sinotubular junction. ${ }^{22}$ The tubular ascending aortic diameter was defined as the maximally dilated portion distal to the sinotubular junction of the ascending aorta. The mid-aortic arch was measured at the level that included 3 branches - the right brachiocephalic, left carotid, and left subclavian arteries. The upper descending thoracic aorta at the level just distal to the aortic arch, the mid-descending thoracic aorta at the level of the pulmonary artery bifurcation, the lower descending thoracic aorta at the level of the left atrium, and the abdominal aorta below the renal artery were measured. The aortic diameter perpendicular to the aortic center line axis at each level in the axial, coronal, or sagittal plane was defined as the maximal dimension.

We compared the characteristics of aortic dissection in patients with and without MFS separately to account for the different pathophysiologic mechanisms underlying the development of dissection. The local institutional review board approved the present observational study and waived the informed consent requirement.

\section{Statistical Analysis}

Continuous variables are expressed as the mean \pm standard deviation or the median and interquartile range and were compared using the independent $t$ test or Wilcoxon rank sum test. Categorical variables were compared using Pearson's chi-square or Fisher's exact test. We used logistic regression analysis to obtain the predicted probability of developing an aortic dissection at an aortic diameter $<55 \mathrm{~mm}$ in non-MFS patients. $P<.05$ in the 2 -tailed test was considered significant. The PASW, version 17.0, statistical analysis software package (SPSS Inc, Chicago, Ill) was used for all analyses.

\section{RESULTS}

The study population included 237 patients with acute type A aortic dissection: 31 patients $(13 \%)$ with MFS and 206 (87\%), who did not present with MFS. The average maximal diameter of the aorta and the baseline characteristics are listed in Table 1. The maximal size of the aortic root, in particular, the sinus of Valsalva, was significantly larger in patients with MFS than in the non-MFS patients (58.6 \pm $15.5 \mathrm{~mm}$ vs $40.2 \pm 6.3 \mathrm{~mm}, P<.001)$. However, the tubular ascending aorta was larger in the non-MFS patients (44.4 mm, interquartile range, 34.3-50.6; vs $35.7 \mathrm{~mm}$, interquartile range, $32.8-42.6 ; P=.001$ ). The maximal size of the whole ascending aorta, including the root and tubular ascending aorta, was significantly larger in the patients with MFS than in the non-MFS patients ( $58.5 \mathrm{~mm}$, interquartile range, $43.8-64.9$; vs $46.7 \mathrm{~mm}$, interquartile range, 42.9-51.6; $P<.001)$. Next, we compared the clinical features stratified by an aortic root diameter of $45 \mathrm{~mm}$ and an ascending aortic diameter of $55 \mathrm{~mm}$, the current guidelines for elective aortic surgery in MFS and non-MFS patients, respectively. Of the MFS patients, $2 / 3(74 \%)$ had a maximal aortic root size of $\geq 45 \mathrm{~mm}$. However, $87 \%$ of the 206 non-MFS patients had a diameter $<55 \mathrm{~mm}$, the current guideline for elective aortic surgery, and $70 \%$ had an aortic diameter $<50 \mathrm{~mm}$.

The clinical and demographic characteristics according to the maximal size of the ascending aorta are listed in Table 2. The patients without MFS who presented with an aortic size $<55 \mathrm{~mm}$ developed aortic dissection at a younger age than those with an aortic size of $\geq 55 \mathrm{~mm}$ (57.2 \pm 11.9 vs $62.7 \pm 15.1$ years, $P=.010$ ). In contrast, the MFS patients tended to develop aortic dissection at an older age with a diameter $<45 \mathrm{~mm}(41.0 \pm 11.9$ vs $28.8 \pm 7.3$ years, $P=.006$ ). Aside from the higher body weight, height, and body mass index in patients whose maximal aorta size was $<55 \mathrm{~mm}$, the baseline characteristics were not significantly different between the groups whose aortic size was $>55 \mathrm{~mm}$ or $<55 \mathrm{~mm}$. The presence of atherosclerosis, penetrating aortic ulcer, and simple renal cyst did not differ according to the size of the aorta in either group. We analyzed whether the independent predictors for the development of aortic dissection at a diameter $<55 \mathrm{~mm}$ existed, particularly in non-MFS patients (Table 3). Univariate analysis revealed that younger patients with a higher body mass index among those with dissection were significantly more likely to experience dissection of the aorta at a smaller diameter. However, hypertension was not an independent predictor of aortic dissection at a smaller diameter $(P=.774)$.

The aortic dissection characteristics according to aortic size are listed in Table 4. The involvement of the aortic 
TABLE 1. Clinical characteristics and aortic measurements in patients with and without Marfan syndrome

\begin{tabular}{|c|c|c|c|}
\hline Variable & $\begin{array}{l}\text { Non-MFS } \\
(\mathbf{n}=\mathbf{2 0 6})\end{array}$ & $\begin{array}{c}\text { MFS } \\
(\mathbf{n}=\mathbf{3 1})\end{array}$ & $P$ value \\
\hline Age & $57.9 \pm 12.4$ & $32.5 \pm 10.1$ & $<.001$ \\
\hline Male gender & $100(48.5)$ & $20(64.5)$ & .097 \\
\hline Weight (kg) & $65.0 \pm 12.1$ & $69.7 \pm 15.4$ & .083 \\
\hline Height (cm) & $162.8 \pm 10.2$ & $180.0 \pm 11.4$ & $<.001$ \\
\hline BMI $\left(\mathrm{kg} / \mathrm{m}^{2}\right)$ & $24.5 \pm 3.2$ & $21.8 \pm 3.8$ & $<.001$ \\
\hline Hypertension & $140(68)$ & $3(9.7)$ & $<.001$ \\
\hline Diabetes & $18(8.7)$ & $2(6.5)$ & 1.000 \\
\hline Atherosclerosis & $118(57.3)$ & $9(29)$ & .003 \\
\hline Penetrating aortic ulcer & $4(1.9)$ & - & 1.000 \\
\hline Simple renal cyst & $54(26.2)$ & - & .001 \\
\hline \multicolumn{4}{|l|}{ Aortic diameter (mm) } \\
\hline \multicolumn{4}{|l|}{ Root } \\
\hline Annulus & $23.8 \pm 3.5$ & $28.8 \pm 6.8$ & $<.001$ \\
\hline Sinus of Valsalva & $40.2 \pm 6.3$ & $58.6 \pm 15.5$ & $<.001$ \\
\hline $\begin{array}{l}\text { Sinotubular } \\
\text { junction }\end{array}$ & $31.7 \pm 7.4$ & $48.0 \pm 13.0$ & $<.001$ \\
\hline $\begin{array}{l}\text { Tubular ascending } \\
\text { aorta }\end{array}$ & $44.4(34.3-50.6)$ & $35.7(32.8-42.6)$ & .001 \\
\hline Aortic arch & $38.2(34.3-41.0)$ & $31.1(27.6-34.1)$ & $<.001$ \\
\hline \multicolumn{4}{|l|}{ Descending aorta } \\
\hline $\begin{array}{l}\text { Upper descending } \\
\text { aorta }\end{array}$ & $36.6(33.5-40.3)$ & $30.6(27.5-38.1)$ & .001 \\
\hline $\begin{array}{l}\text { Mid-descending } \\
\text { aorta }\end{array}$ & $34.1(31.2-37.2)$ & $29.5(26.2-33.2)$ & $<.001$ \\
\hline $\begin{array}{l}\text { Lower descending } \\
\text { aorta }\end{array}$ & $32.5(29.3-35.0)$ & $26.6(23.4-30.8)$ & $<.001$ \\
\hline Abdominal aorta & $29.1(26.7-31.9)$ & $26.5(23.6-30.0)$ & .006 \\
\hline $\begin{array}{l}\text { Maximal diameter of } \\
\text { ascending aorta }\end{array}$ & $46.7(42.9-51.6)$ & $58.5(43.8-64.9)$ & $<.001$ \\
\hline
\end{tabular}

root was more frequent, not only in patients with MFS with an aortic size of $\geq 45 \mathrm{~mm}$ compared with those with $<45 \mathrm{~mm}(73.9 \%$ vs $0 \%, P<.001)$, but also in patients without MFS with an aortic size of $\geq 55 \mathrm{~mm}$ compared with those with $<55 \mathrm{~mm}(70 \%$ vs $39 \%, P=.003)$. However, dissection at the smaller aortic size started most often at the tubular ascending level, regardless of MFS. The degree of flap extension differed according to aortic size in non-MFS patients but not in the MFS patients. The MFS patients had a dissected flap that mainly extended to the distal iliac artery, regardless of aortic size. Dissection in non-MFS patients with an aortic size $<55 \mathrm{~mm}$ had more frequently extended to the distal iliac artery than in those with an aortic size of $\geq 55 \mathrm{~mm}$, for whom dissection was limited to the level of the low descending thoracic aorta $(P=.001)$.

The size distribution according to the level of the aorta at presentation with acute aortic dissection is shown in Figure 1 . In contrast to the MFS patients, who usually developed dissection at the dilated aorta, the non-MFS patients mostly experienced dissection in the region of smaller aortic size (all $P<.05$ ). This finding was similar in each segment of the ascending aorta, including at the level of the sinus of Valsalva and the tubular ascending segment. Most non-MFS patients presented with aortic dissection at a smaller size of the mid-ascending aorta and the sinus of Valsalva.

\section{DISCUSSION}

According to a previous study, the median aortic diameter at rupture or dissection of the ascending aorta or aortic arch was about $60 \mathrm{~mm}$. They also reported a progressively increasing risk of rupture, dissection, or death, culminating in $16 \%$ for an aortic diameter $>60 \mathrm{~mm} .^{8}$ Therefore the accepted critical aortic diameter at any age might be 50 to $55 \mathrm{~mm}$, and it has been suggested that intervention is advisable at an aortic size $>55 \mathrm{~mm}$ in anticipation of subsequent dissection. ${ }^{4}$ However, recent reports have suggested that the absolute size of the aorta might not be an appropriate indicator for elective aortic replacement. ${ }^{13,23}$

Our data have suggested that the aortic size has limited value for predicting type A aortic dissection in non-MFS

TABLE 2. Comparison of clinical and demographic characteristics of patients with aortic dissection according to maximal ascending aorta size

\begin{tabular}{|c|c|c|c|c|c|c|}
\hline \multirow[b]{2}{*}{ Variable } & \multicolumn{3}{|c|}{ Non-MFS } & \multicolumn{3}{|c|}{ MFS } \\
\hline & $<55 \mathrm{~mm}(\mathrm{n}=\mathbf{1 7 9})$ & $\geq 55 \mathrm{~mm}(\mathrm{n}=\mathbf{2 7})$ & $P$ value & $<45 \mathrm{~mm}(\mathrm{n}=8)$ & $\geq 45 \mathrm{~mm}(\mathrm{n}=23)$ & $P$ value \\
\hline Age & $57.2 \pm 11.9$ & $62.7 \pm 15.1$ & .010 & $41.0 \pm 11.9$ & $28.8 \pm 7.3$ & .006 \\
\hline Male gender & 89 (49.7) & $11(40.7)$ & .384 & $5(62.5)$ & $15(65.2)$ & 1.000 \\
\hline Weight (kg) & $66.0 \pm 12.1$ & $58.5 \pm 10.3$ & .002 & $70.3 \pm 11.3$ & $70.8 \pm 16.5$ & .903 \\
\hline Height $(\mathrm{cm})$ & $163.4 \pm 10.0$ & $159.3 \pm 10.6$ & .029 & $177.7 \pm 11.1$ & $180.7 \pm 11.6$ & .540 \\
\hline BMI $\left(\mathrm{kg} / \mathrm{m}^{2}\right)$ & $24.9 \pm 3.1$ & $22.3 \pm 3.0$ & .001 & $22.2 \pm 1.9$ & $21.6 \pm 4.3$ & .354 \\
\hline Hypertension & $121(67.6)$ & $19(70.4)$ & .773 & - & $3(13.0)$ & .550 \\
\hline Diabetes & $13(7.3)$ & $5(18.5)$ & .067 & - & $2(8.7)$ & 1.000 \\
\hline Coronary artery disease & $1(0.6)$ & $1(3.7)$ & .246 & - & - & - \\
\hline Atherosclerosis & $98(54.7)$ & $20(74.1)$ & .058 & $4(50.0)$ & $5(21.7)$ & .185 \\
\hline Penetrating aortic ulcer & $3(1.7)$ & $1(3.7)$ & .432 & - & - & - \\
\hline Simple renal cyst & $47(26.3)$ & $7(25.9)$ & .971 & - & - & - \\
\hline
\end{tabular}

Data are presented as mean $\pm \mathrm{SD}$ or $\mathrm{n}(\%) . M F S$, Marfan syndrome; $B M I$, body mass index. 
TABLE 3. Independent predictors of aortic dissection at a diameter $<55 \mathbf{~ m m}$ in non-MFS patients

\begin{tabular}{lccc}
\hline \multicolumn{1}{c}{ Variable } & OR & \multicolumn{1}{c}{$\mathbf{9 5} \%$ CI } & $\boldsymbol{P}$ value \\
\hline Age & 0.962 & $0.928-0.97$ & .035 \\
BMI & 1.376 & $1.149-1.647$ & .001 \\
Hypertension & 0.878 & $0.363-2.125$ & .774 \\
Atherosclerosis & 0.423 & $0.171-1.052$ & .064 \\
Penetrating aortic ulcer & 0.443 & $0.044-4.422$ & .488 \\
Simple renal cyst & 1.017 & $0.404-2.560$ & .971 \\
\hline
\end{tabular}

OR, Odds ratio; $C I$, confidence interval; $M F S$, Marfan syndrome; $B M I$, body mass index

patients. We found that most dissections in non-MFS patients occurred with a much smaller aortic size than previously reported. Specifically, only $13 \%$ of non-MFS patient had an ascending aortic size of $\geq 55 \mathrm{~mm}$ at presentation with acute type A aortic dissection. When we compared the ratio of the size of the ascending and descending aorta, rather than an absolute size of $55 \mathrm{~mm}$, most nonMFS patients with dissection also had a relatively small ascending aortic size (data not shown). In contrast, patients with MFS were less likely to experience dissection at smaller diameters. Although we obtained these findings only from Asian patients, several previous Western studies have supported our results that the aortic size has a limited role in the genesis of acute type A aortic dissection. ${ }^{12,13,23}$ Most of the patients with MFS presented with aortic dissection at a size of $\geq 45 \mathrm{~mm}$, the current recommendation for prophylactic replacement of the aorta. Currently, most clinicians examine the aortic root size of MFS patients using echocardiography, computed tomographic angiography, and magnetic resonance angiography to prevent aortic rupture or dissection, on at least an annual basis. In our analysis, most young patients with MFS presented with aortic dissection after the aorta had dilated to $>45 \mathrm{~mm}$, and older patients tended to experience dissection at an aortic size of $<45 \mathrm{~mm}$.
These results suggest that older patients with MFS should be monitored for aortic dissection more carefully, even at smaller aortic diameters.

Risk factors for aortic dissection in patients with a normal aortic diameter were not found in our study. In contrast to the results from the International Registry of Aortic Dissection, hypertension was not related to dissection at a diameter $<55 \mathrm{~mm}$. The incidence of atherosclerosis and penetrating aortic ulcer, known risk factors for aortic dissection, did not differ between the patients with dissection and an aortic size $<55 \mathrm{~mm}$ and those with dissection and a size of $\geq 55 \mathrm{~mm}$. The non-MFS patients with acute type A aortic dissection at $<55 \mathrm{~mm}$ tended to be younger and to have a higher body mass index. However, we were unable to identify any possible factors elucidating its mechanisms. Additional studies are required to explain why some patients with a normal ascending aorta diameter, with or without MFS, developed type A aortic dissection.

Although $87 \%$ of aortic dissections in non-MFS patients occurred at a size less than the recommended surgical criterion of $55 \mathrm{~mm}$, we cannot recommend a size criterion for surgical intervention below this threshold. Because it is likely that a significant number of patients have an aortic size of 40 to $55 \mathrm{~mm}$, the rate of dissection in these patients would be very small, and one could certainly cause harm by performing prophylactic surgery on all of them. ${ }^{24}$ Although the aortic size is a very helpful criterion for determining the need for aortic intervention, clinicians should not overlook patients with a small aortic size, especially those without MFS.

\section{Study Limitations}

The present study was limited primarily by the use of observational data. However, our study was one of the largest studies of its type to date, with 237 patients with acute type A aortic dissection.

TABLE 4. Characteristics of acute type A aortic dissection with and without MFS according to maximal ascending aorta size

\begin{tabular}{|c|c|c|c|c|c|c|}
\hline \multirow[b]{2}{*}{ Variable } & \multicolumn{3}{|c|}{ Non-MFS } & \multicolumn{3}{|c|}{ MFS } \\
\hline & $<55 \mathrm{~mm}(\mathrm{n}=179)$ & $\geq 55 \mathrm{~mm}(\mathrm{n}=27)$ & $P$ value & $<45 \mathrm{~mm}(\mathrm{n}=8)$ & $\geq 45 \mathrm{~mm}(\mathrm{n}=23)$ & $P$ value \\
\hline Starting site of dissection & & & .003 & & & $<.001$ \\
\hline Aortic root & $69(38.5)$ & $19(70.4)$ & & - & $17(73.9)$ & \\
\hline Mid-ascending aorta & $110(61.5)$ & $8(29.6)$ & & $8(100.0)$ & $6(26.1)$ & \\
\hline Flap extending to & & & .001 & & & .459 \\
\hline Tubular ascending aorta & $10(5.6)$ & $5(18.5)$ & & - & $5(21.7)$ & \\
\hline Aortic arch & $12(6.7)$ & $3(11.1)$ & & - & $2(8.7)$ & \\
\hline UDTA & 0 & $1(3.7)$ & & - & - & \\
\hline MDTA & $8(4.5)$ & $5(18.5)$ & & - & $2(8.7)$ & \\
\hline LDTA & $17(9.6)$ & $2(7.4)$ & & $1(12.5)$ & $3(13.0)$ & \\
\hline Abdominal aorta & $15(8.4)$ & $2(7.4)$ & & - & $1(4.3)$ & \\
\hline Iliac artery & $116(65.2)$ & $9(33.3)$ & & $7(87.5)$ & $10(43.5)$ & \\
\hline
\end{tabular}

UDTA, Upper descending thoracic aorta; MDTA, mid-descending thoracic aorta; LDTA, lower descending thoracic aorta; MFS, Marfan syndrome. 


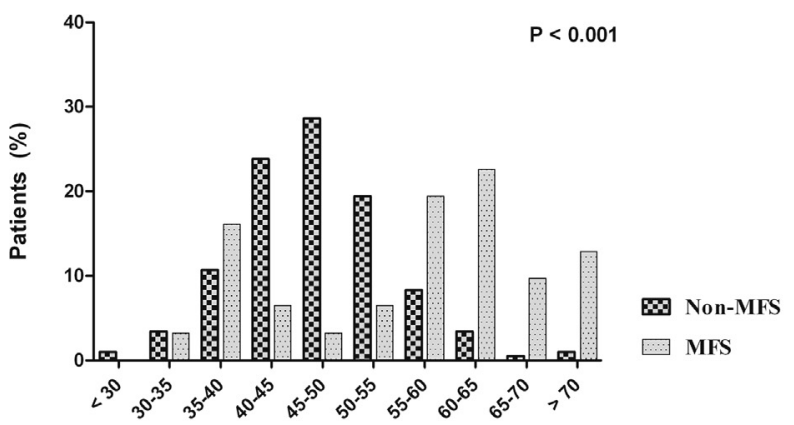

A

Maximal aortic diameter $(\mathrm{mm})$
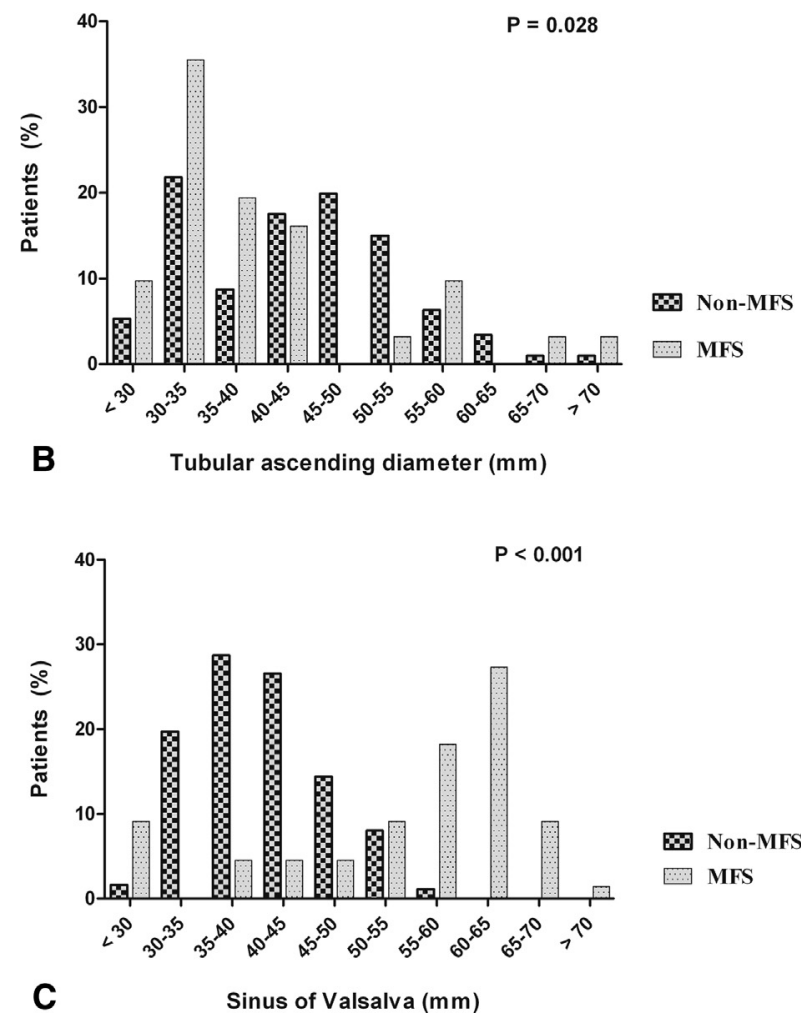

FIGURE 1. Distribution of aortic diameters at presentation with acute type A aortic dissection. A, Maximal diameter of the whole length of the aorta. B, Maximal diameter of the tubular ascending aorta. C, Maximal diameter of the sinus of Valsalva of the aorta. MFS, Marfan syndrome.

Additionally, we examined the aortic diameter at presentation. The difference between the size of the aorta at the moments before and after dissection has not been studied in patients with aortic dissection. One experimental study demonstrated a $140 \%$ increase in the circumference after they had induced aortic dissection in human and porcine cadaver specimens. ${ }^{25}$ Therefore, it is highly likely that the diameter before dissection would be smaller than the measured diameter after dissection in our study. Thus, the actual diameter of the predissected aorta would be much smaller than the aortic diameter recommended for elective surgery in non-MFS patients.

\section{CONCLUSIONS}

The findings of the present study have suggested that most dissection in non-MFS patients occurs with a smaller aortic size than previously reported. The findings of the present study support a substantial prevalence of exposure to aortic dissection at a smaller aortic diameter. Although the aortic size can be a very helpful criterion for determining the need for aortic intervention, clinicians should not overlook patients with a small aortic size, especially those without MFS.

\section{References}

1. Hagan PG, Nienaber CA, Isselbacher EM, Bruckman D, Karavite DJ, Russman PL, et al. The International Registry of Acute Aortic Dissection (IRAD): new insights into an old disease. JAMA. 2000;283:897-903.

2. Januzzi JL, Isselbacher EM, Fattori R, Cooper JV, Smith DE, Fang J, et al. Characterizing the young patient with aortic dissection: results from the International Registry of Aortic Dissection (IRAD). J Am Coll Cardiol. 2004;43:665-9.

3. Cho JR, Shin S, Kim JS, Ko YG, Hong HK, Jang Y, et al. Clinical characteristics of acute aortic syndrome in Korean patients: from the Korean multi-center registry of acute aortic syndrome. Korean Circ J. 2012;42:528-37.

4. Erbel R, Alfonso F, Boileau C, Dirsch O, Eber B, Haverich A, et al. Diagnosis and management of aortic dissection. Eur Heart J. 2001;22:1642-81.

5. Coady MA, Rizzo JA, Hammond GL, Kopf GS, Elefteriades JA. Surgical intervention criteria for thoracic aortic aneurysms: a study of growth rates and complications. Ann Thorac Surg. 1999;67:1922-6.

6. Gott VL, Greene PS, Alejo DE, Cameron DE, Naftel DC, Miller DC, et al. Replacement of the aortic root in patients with Marfan's syndrome. $N$ Engl J Med. 1999;340:1307-13.

7. Ergin MA, Spielvogel D, Apaydin A, Lansman SL, McCullough JN, Galla JD, et al. Surgical treatment of the dilated ascending aorta: when and how? Ann Thorac Surg. 1999;67:1834-9.

8. Sabik JF, Lytle BW, Blackstone EH, McCarthy PM, Loop FD, Cosgrove DM Long-term effectiveness of operations for ascending aortic dissections. J Thorac Cardiovasc Surg. 2000;119:946-62.

9. Chiappini B, Schepens M, Tan E, Dell'Amore A, Morshuis W, Dossche K, et al. Early and late outcomes of acute type A aortic dissection: analysis of risk factors in 487 consecutive patients. Eur Heart J. 2005;26:180-6.

10. Sutsch G, Jenni R, von Segesser L, Turina M. Predictability of aortic dissection as a function of aortic diameter. Eur Heart J. 1991;12:1247-56.

11. Trimarchi S, Jonker FH, Hutchison S, Isselbacher EM, Pape LA, Patel HJ, et al. Descending aortic diameter of $5.5 \mathrm{~cm}$ or greater is not an accurate predictor of acute type B aortic dissection. J Thorac Cardiovasc Surg. 2011;142: 101-7.

12. Parish LM, Gorman JH III, Kahn S, Plappert T, St John-Sutton MG, Bavaria JE, et al. Aortic size in acute type A dissection: implications for preventive ascending aortic replacement. Eur J Cardiothorac Surg. 2009;35:941-6.

13. Pape LA, Tsai TT, Isselbacher EM, Oh JK, O'Gara PT, Evangelista A, et al Aortic diameter $\geq 5.5 \mathrm{~cm}$ is not a good predictor of type a aortic dissection: observations from the International Registry of Acute Aortic Dissection (IRAD). Circulation. 2007;116:1120-7.

14. Barbetseas J, Alexopoulos N, Brili S, Aggeli C, Chrysohoou C, Frogoudaki A et al. Atherosclerosis of the aorta in patients with acute thoracic aortic dissection. Circ J. 2008;72:1773-6.

15. Kim EK, Choi ER, Song BG, Jang SY, Ko SM, Choi SH, et al. Presence of simple renal cysts is associated with increased risk of aortic dissection: a common manifestation of connective tissue degeneration? Heart. 2010;97:55-9.

16. Sundt $\mathrm{T}$. Intramural hematoma and penetrating atherosclerotic ulcer of the aorta. Ann Thorac Surg. 2007;83:S835-41.

17. Kimura S, Noda M, Usui M, Isobe M. Diagnostic criteria for penetrating atheromatous ulcer of the thoracic aorta. Ann Thorac Surg. 2004;78:1070-2.

18. Lu TL, Huber CH, Rizzo E, Dehmeshki J, von Segesser LK, Qanadli SD Ascending aorta measurements as assessed by ECG gated multi-detector computed tomography: a pilot study to establish normative values for transcatheter therapies. Eur Radiol. 2009;19:664-9.

19. Ocak I, Lacomis JM, Deible CR, Pealer K, Parag Y, Knollmann F. The aortic root: comparison of measurements from ECG-gated CT angiography with transthoracic echocardiography. J Thorac Imaging. 2009;24:223-6. 
20. Yoo SM, Rho JY, Lee HY, Song IS, Moon JY, White CS. Current concept in cardiac CT angiography for patients with acute chest pain. Korean Circ J. 2010;40:543-9.

21. Aronberg DJ, Glazer HS, Madsen K, Sagel SS. Normal thoracic aortic diameters by computed tomography. J Comput Assist Tomogr. 1984;8:247-50.

22. Anderson RH, Lal M, Ho SY. Anatomy of the aortic root with particular emphasis on options for its surgical enlargement. J Heart Valve Dis. 1996;5:S249-57.
23. Neri E, Barabesi L, Buklas D, Vricella LA, Benvenuti A, Tucci E, et al. Limited role of aortic size in the genesis of acute type A aortic dissection. Eur $J$ Cardiothorac Surg. 2005;28:857-63.

24. Elefteriades JA, Farkas EA. Thoracic aortic aneurysm clinically pertinent controversies and uncertainties. J Am Coll Cardiol. 2010;55:841-57.

25. Williams DM, LePage MA, Lee DY. The dissected aorta. Part I. Early anatomic changes in an in vitro model. Radiology. 1997;203:23-31. 